\title{
New Intracanal Formulations Containing Doxycycline or Chlorhexidine Against Enterococcus faecalis
}

\author{
${ }^{1}$ Ana Rita Marques da Silva, ${ }^{2}$ Shelon Cristina Souza Pinto, ${ }^{3}$ Elizabete Brasil dos Santos, ${ }^{4}$ Fábio André dos Santos, \\ ${ }^{5}$ Paulo Vitor Farago, ${ }^{6}$ João Carlos Gomes, ${ }^{7}$ Irene Pina-Vaz, ${ }^{8}$ Manuel Fontes Carvalho
}

\begin{abstract}
The present study aims to evaluate the antimicrobial effect of two new intracanal preparations against $E$. faecalis. Thirty single-rooted human canine teeth were used. The crowns were removed and the roots were instrumented using a conventional technique. Three groups of ten teeth each were infected with $108 \mathrm{CFU} / \mathrm{ml}$ of $E$. faecalis for 21 days. The root canals were filled with new intracanal medications containing $3 \%$ doxycycline hydrochloride (DX) or $2 \%$ chlorhexidine digluconate (CHX). Ten teeth received no medication (NM)-negative control. Microbial samples were obtained 21 days after contamination: 14 days under the effect of the intracanal medications and 7 days after replacing the medications by $\mathrm{BHI}$ broth. The samples were homogenized, diluted, seeded on $\mathrm{BHI}$ agar and incubated for $48 \mathrm{~h} / 36^{\circ} \mathrm{C}$. The number of colony forming units $(\mathrm{CFU} / \mathrm{ml})$ was obtained and analyzed statistically. All intracanal dressings significantly reduced the number of bacterial cells in the root canal after 14 days with medication. After the period with 7 days with $\mathrm{BHI}$ broth, the CFU counts of $E$. faecalis remained at low values. However, the NM group showed a significant increase of CFU in this period to similar values of the initial contamination. $3 \%$ doxycycline hydrochloride gel and $2 \% \mathrm{CHX}$ gel were effective to eliminate $E$. faecalis from the root canal system.
\end{abstract}

Keywords: Endodontics, Enterococcus faecalis, Doxycycline, Chlorhexidine.

How to cite this article: da Silva ARM, Pinto SCS, dos Santos EB, dos Santos FA, Farago PV, Gomes JC, Pina-Vaz I, Carvalho MF. New Intracanal Formulations Containing Doxycycline or Chlorhexidine Against Enterococcus faecalis. J Contemp Dent Pract 2014;15(1):61-65.

Source of support: Nil

Conflict of interest: None declared

\section{INTRODUCTION}

The species Enterococcus faecalis is one of the pathogens that shows high resistance to a wide range of antimicrobial

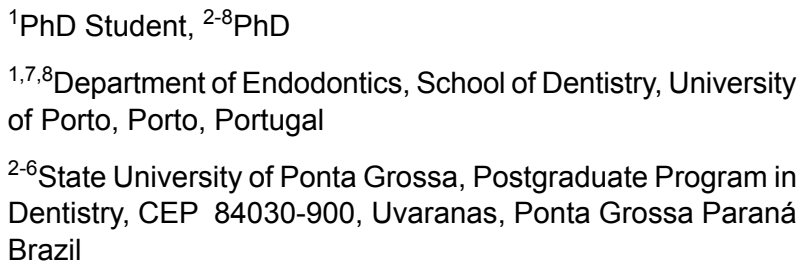

${ }^{2-6}$ State University of Ponta Grossa, Postgraduate Program in Dentistry, CEP 84030-900, Uvaranas, Ponta Grossa Paraná Brazil

Corresponding Author: Ana Rita Marques da Silva, PhD Student, Department of Endodontics, Rua Comandante Sacadura Cabral ${ }^{\circ}$ 22-3030-333, Coimbra-Portugal, e-mail: anaritavlis@gmail.com agents used in root canal treatment. This microorganism is a Gram-positive bacterium that can be found in the oral cavity and is frequently isolated from root filled teeth with persistent lesions ${ }^{1}$ leading to the failure of endodontic therapy.

Once these bacteria have infected the dentinal tubules, their eradication is very difficult even with the use of several irrigation solutions and medications during endodontic treatment. This could be due to their ability to invade and attach to the dentinal tubules as organized biofilms. ${ }^{2}$

The aim of root canal treatment is to disinfect and to eliminate the bacteria from the root canal system, or at least reduce the bacterial counts to a very low level so it could be possible to prevent periapical disease or the need for treatment. ${ }^{3}$ In order to achieve this purpose, several antiseptic irrigation solutions and intracanal medications are often used during the root canal treatment in combination with mechanical instrumentation.

Despite the great variety of intracanal medications, the search for a potent substance with a high antimicrobial spectrum and low cytotoxicity continues to be a relevant issue.

A promising candidate is $\mathrm{CHX}$, which is commonly used in periodontics due to its broad spectrum antibacterial activity. ${ }^{4}$ Some studies propose its use in endodontics too, as an irrigant or intracanal dressing. ${ }^{5,6}$ Its antibacterial spectrum includes most of the microorganisms present in the oral cavity, such as Gram-positive and Gram-negative bacteria, bacterial spores, lipophilic viruses, yeasts and dermatophytes. ${ }^{7-9}$ Chlorhexidine has also the ability to inhibit dentin matrix metaloproteinase, ${ }^{7}$ presents a high substantivity ${ }^{8,10}$ and is more effective in eliminating E. faecalis from dentinal tubules than calcium hydroxide. ${ }^{11,12}$

Tetracyclines are a group of broad-spectrum antibiotics effective against a wide range of microorganisms. They are bacteriostatic, which provides a more advantageous use since there is no bacterial lysis and consequently no release of antigenic by-products such as endotoxins. ${ }^{13}$ Besides the antibacterial activity, tetracyclines have anti-inflammatory properties with several intracellular and extracellular effects. ${ }^{14}$ These antibiotics have already been used in endodontics as irrigants of root-end cavity and as intracanal medicaments. ${ }^{15}$ Anew irrigant solution, MTAD, ${ }^{13}$ containing a mixture of $3 \%$ doxycycline, $4,25 \%$ citric acid and a detergent $(0.5 \% \text { Polysorbate } 80)^{16}$ was also introduced and 
some studies suggest that MTAD has a potent antibacterial effect against E. faecalis. ${ }^{17,18}$ MTAD presents an acidic condition $(\mathrm{pH}=2.15)$, which could explain the changes on the structure of the dentinal tubules, helping its diffusion through them. ${ }^{19}$

After these considerations, the aim of this study was to create an innovative intracanal dressing gels based on the formulation of MTAD containing doxycycline, along with another one containing chlorhexidine, to compare their ability to eliminate $E$. faecalis from root canals.

\section{MATERIALS AND METHODS}

The same operator has prepared all the medications and the substances tested were:

Three percent doxycycline gel-DX (3.33 g doxycycline hydrochloride; $0.1 \mathrm{~g}$ sodium metabisulfite; $50 \%$ propylene glycol; $0.5 \%$ polysorbate $80 ; 0.76 \% \mathrm{NaH}_{2} \mathrm{PO}_{4} ; 1.94 \%$ $\mathrm{Na}_{2} \mathrm{HPO}_{4}$, and $43.37 \mathrm{~g} \%$ hydroxyethylcellulose gel)-2\% chlorhexidine digluconate gel-CHX (10 g 20\% chlorhexidine digluconate; $50 \%$ propylene glycol; $0.5 \%$ polysorbate 80 and $39.5 \mathrm{~g} \%$ hydroxyethylcellulose gel).

The specie of microorganism used was $E$. faecalis (ATCC \#29203) that was grown on Brain Heart Infusion Agar plates (BHI). Gram staining and colony morphology were used to confirm the purity of the positive cultures of E. faecalis.

The method followed in this study was a modification of the one described by Gomes et al and Lima et al. ${ }^{20,21}$ Thirty extracted human canine teeth were selected and the presence of a single root canal was confirmed radiographically. Curettes were used to remove soft tissues and debris from teeth surfaces and when any kind of anomaly, such as a fracture, was detected, the tooth was excluded from this study. Teeth crowns were removed $3 \mathrm{~mm}$ above the cementoenamel junction and the roots were standardized to a length of $15 \mathrm{~mm}$ with a water-cooled diamond saw. A size $10 \mathrm{~K}$-file was introduced into each canal until it could be seen at the apical foramen. The working length was established subtracting $1 \mathrm{~mm}$ from this measurement $(14 \mathrm{~mm})$. In order to preserve patency, the same K-file was used to recapitulate the canal $1 \mathrm{~mm}$ beyond its length between each file. The anatomic diameter of apical foramen was sized using manual K-files (DentSply/Maillefer), beginning with size 10 files, inserted until the working length was reached. Files' sizes were progressively increased until obtaining an instrument that bound at the working length. The size of the instrument obtained was recorded for each root. $^{22}$ The roots were enlarged with K-files, three numbers up to apical file size determined at the working length.

The teeth were instrumented using the crown-down principles, combining Gates Glidden drills with K-files. The cervical two-third $(10 \mathrm{~mm})$ of the canals were prepared using K-files 25 to 35 , followed by a size 2 Gates Glidden bur and then by a size $3,1 \mathrm{~mm}$ shorter. The apical stop was established using files three numbers up to the anatomic diameter file. At each file change the root canals were irrigated with $1 \mathrm{ml}$ of $5.25 \% \mathrm{NaOCl}$. After mechanical preparation, the teeth were rinsed with $5 \mathrm{ml}$ of $17 \%$ ethylenediamine tetra-acetic acid (EDTA) solution for 3 minutes, to remove the smear layer, followed by $1 \mathrm{ml}$ $5.25 \%$ of $\mathrm{NaOCl}$ and finally with $5 \mathrm{ml}$ of saline solution.

The teeth were placed into glass tubes containing $5 \mathrm{ml}$ of brain heart infusion (BHI) broth, autoclaved at $121^{\circ} \mathrm{C}$, for 30 minutes and then incubated at $36^{\circ} \mathrm{C}$ for 24 hours to confirm sterility. ${ }^{8,10}$ Once confirmed, the teeth were randomly divided in three groups according to their anatomic diameter. Two milliliters of BHI were removed from the tubes and replaced by $2 \mathrm{ml}$ of a suspension of $E$. faecalis (ATCC \#29203), containing 108 cells/ml, standardized by spectrophotometry and McFarland scale. The tubes were again incubated at $36^{\circ} \mathrm{C}$ for 21 days.

In order to avoid saturation of the media during this contamination period of 21 days, $2 \mathrm{ml}$ of contaminated BHI were replaced by $2 \mathrm{ml}$ of freshly prepared broth, every 2 days. After the contamination period the specimens were fixed in a sterile aluminum apparatus and were irrigated with sterile saline. They were dried with 3 paper points, calibrated with the last file used along the full length of the canal $(14 \mathrm{~mm})$. The third paper points were kept inside the canal for 60 seconds and were used to recover E. faecalis from the root canal. They were transferred to vials containing $1 \mathrm{ml}$ of saline solution, homogenized and $100 \mu \mathrm{l}$ seeded on $\mathrm{BHI}$ agar plates. The number of $\mathrm{CFU} / \mathrm{ml}$ was obtained after incubation at $36^{\circ} \mathrm{C} / 48$ hours.

\section{Intracanal Dressings and E. faecalis Recovery from Root Canal}

After the first bacterial sampling, the root canals were filled with the proposed medicaments. The intracanal dressings DX and CHX were applied using a syringe and needle with the specimens fixed in the aluminum apparatus. The medication excess was removed and the coronal and apical communications were sealed with sterile sticky wax. In the negative control (NM), the coronal and apical communications of the root canals with no medication were also sealed with sterile sticky wax. The teeth were then fixed with sticky wax at the bottom of the wells of the cell culture plates. The wells were filled with BHI broth up to the dental-enamel junction, covered with humid sterile gauzes and incubated at $36^{\circ} \mathrm{C}$ for 14 days (Fig. 1). ${ }^{20,23}$

The second sampling was made by the same method after 14 days of intracanal dressing. Before collection of the samples and under aseptic conditions, the specimens were 
fixed in the sterile aluminum apparatus, irrigated with sterile saline, neutralized with a solution of $0.5 \%$ Tween $80 \%$ in $0.07 \%$ soy lecithin and again irrigated with sterile saline. ${ }^{23}$ After fixing the specimens in the 24-well cell culture plates with sterile sticky wax, the canals where filled with BHI broth and the coronal surface was sealed with the sticky wax. The wells were filled with BHI broth up to the dentalenamel junction and covered with humid sterile gauzes and the plates were incubated at $36^{\circ} \mathrm{C}$ for 7 days, when the third group of samples was obtained, using the same procedures applied to both anterior samplings.

The data were statistically analyzed using analysis of variance with repeated measures (ANOVA) to indicate differences among the experimental groups.

\section{RESULTS}

Table 1 shows the number of CFU/ml of E. faecalis recovered from root canals after the 3 experimental periods. After 21 days of contamination, E faecalis was recovered from all teeth.

The mean values of CFUs decreased in all groups after 14 days with intracanal dressings. However, the difference was higher in the groups with intracanal dressings DX and CHX, when compared to the NM group.

After 7 days with BHI inside the root canals, the CFU numbers remained low in the groups DX and CHX, while in the NM group the CFU counting returned to the initial level. The Kinetics description of these 3 moments of the experiment can be seen in the Figure 2.

In order to test if these changes over time were statistically significant, a repeated measure ANOVA, assuming the significant value of at least 0.05 was used. The assumption of normality and homogeneity of variance was also tested, using Mauchly's sphericity test, allowing us to proceed with correction of Greenhouse-Geisser.

The repeated measures ANOVA showed a significant difference between CFU during the different moments of time $(p<0.0001)$, and that even the interaction between time and groups was significant $(\mathrm{p}=0.012)$. Looking inside each group, all revealed significant differences (NM $\mathrm{p}=0.010$, DX $p=0.031$ and CHX $p<0.001)$. Between the first and the second moment all groups exhibited a reduction of the amount of CFU, where it was noticed a significant difference between DX $(p=0.999)$ and CHX $(p=0.015)$. Yet in the NM group the difference was not enough to indicate statistical significance. After the second moment the CHX and DX group reduced the number of CFU, but it was not enough to indicate statistical difference, however in the NM it was revealed a significant increase of UFC $(p=0.006)$.

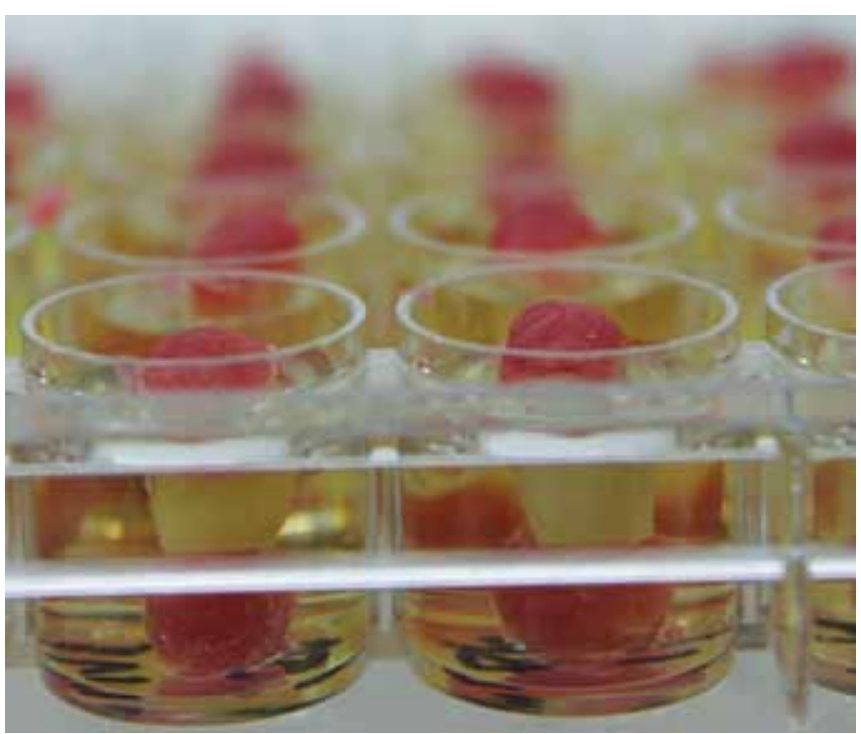

Fig. 1: Cell culture plates filled with $\mathrm{BHI}$ broth and specimens fixed with sticky wax

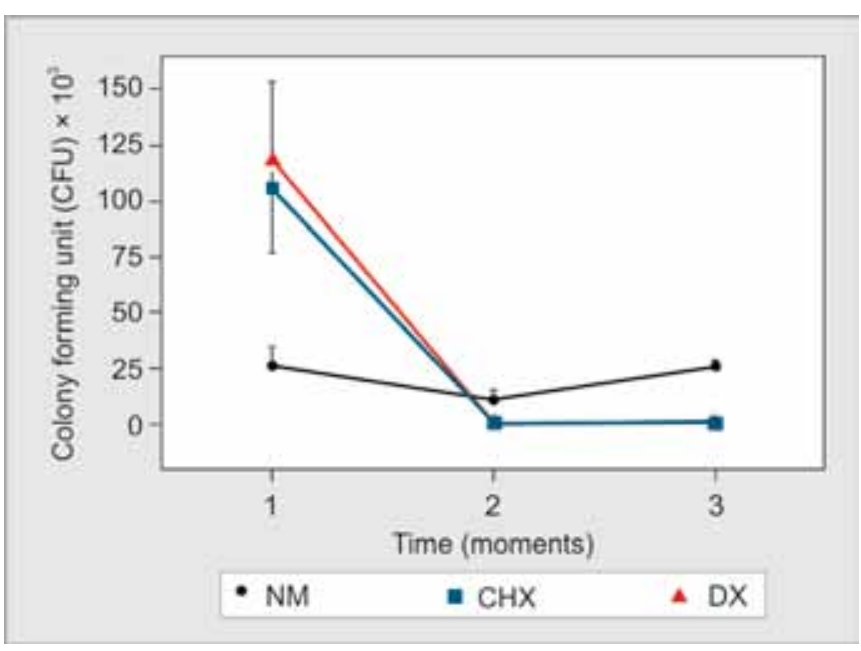

Fig. 2: Kinetics of groups/medications versus time: (1) 1st momentafter 21 days of contamination with $E$. faecalis, (2) 2nd-after 14 days with the intracanal medication, (3) 3rd moment- after 7 days with $\mathrm{BHI}$ broth. Repeated measures, ANOVA, to analyze time and the interaction time versus group

Table 1: Mean value of CFU's (CFU/ml) of the two intracanal medicaments during the three moments of the experiment

\begin{tabular}{llll}
\hline & \multicolumn{3}{c}{ Experimental groups $\left(\mathrm{CFU} / \mathrm{ml} \times 10^{4}\right)$} \\
\hline Bacterial samplings $^{*}$ & No Medication $(N M)(n=10)$ & Doxycycline $(n=10)$ & Chlorhexidine $(n=10)$ \\
\hline $1^{\circ}(21$ days $)$ & $2.63 \pm 2.77$ & $11.89 \pm 10.95$ & $10.59 \pm 9.17$ \\
$2^{\circ}(14$ days $)$ & $1.12 \pm 1.37$ & $0.17 \pm 0.19$ & $0.08 \pm 0.21$ \\
$3^{\circ}(7$ days $)$ & $2.63 \pm 0.86$ & $0.11 \pm 0.11$ & $0.02 \pm 0.02$ \\
\hline
\end{tabular}

${ }^{*}$ Time $F(1.009)=25.087 ; p=0.000$

Time $\times$ Group/Medication F $(2.018)=5.231 ; p=0.012$

1st-21 days of contamination with $E$. faecalis; 2nd-14 days filled with the medications and 3rd-7days filled with $\mathrm{BHI}$ 


\section{DISCUSSION}

In the present study, after 14 days with medication with doxycycline or chlorhexidine, the numbers of $E$. faecalis dropped off substantially, indicating that both intracanal dressing gels presented similar antibacterial efficacy, without significant difference between these groups. This antimicrobial activity against E. faecalis has also been demonstrated by others authors, both through an irrigating solution with Doxicycline (MTAD) or a chlorhexidine dressing. ${ }^{24,25}$

After 7 days with BHI broth inside the root canal, the DX and CHX groups continued to present a decrease in CFU numbers. These results suggest some substantivity, which is the prolonged and gradual release of a material at therapeutic levels in a substrate, higher than would be expected from a simple deposition mechanism. In the root canal treatment it is important to use irrigants and specially dressings with a residual antimicrobial activity, to prevent re-infection and improve the outcome of the treatment. ${ }^{26}$

In the NM group the number of CFU has increased significantly after the same period, equalling the number of the initial counting.

The use or not of BHI broth outside the roots is not universal. ${ }^{20,23}$ We choose to fill the well with BHI because some literature suggests that bacteria within radicular dentinal tubules may use the tissue fluid from periodontal ligament and alveolar bone to get the nutrients that they need to survive. ${ }^{1,27}$

The significant difference observed in the numbers of CFU between the three groups after the 21 days of contamination, could be explained by the complex variability of the root canal structure, ${ }^{28}$ since this method has already been used in other studies. ${ }^{20,21}$

In this study, DX was very effective in eliminating E. faecalis from the root canal system. The efficacy of this antibiotic has been demonstrated in a new root canal irrigant solution called MTAD. ${ }^{13,29}$ Our formulation, as in MTAD, contains also a detergent (Tween 80) that decreases the surface tension and improves its penetration through the dentinal tubules. ${ }^{18}$ Although the DX was very similar to MTAD, its consistency has been changed, together with the $\mathrm{pH}$, turning it from acidic to neutral. This property is important because although DX will remain in the root canal for a longer time, a higher $\mathrm{pH}$ will avoid dentin structure damage. ${ }^{33,34}$

The recommended concentration of chlorhexidine in endodontics is $2 \%^{30,31}$ and it can be used in both forms, liquid or gel. ${ }^{32}$ Chlorhexidine gel is soluble, easy to remove and does not interfere with the sealing ability of obturation cements. ${ }^{33}$ Chlorhexidine has some disadvantages, such as the precipitate that forms with the interaction with sodium hypochlorite ${ }^{34}$ and the deposition of extrinsic stains in the teeth. ${ }^{35}$ In this way it is also advisable to look for alternatives.

This study has just tested single specie of microorganism (E. faecalis) to evaluate the intracanal medication. Nevertheless, the results of this investigation indicate that the new intracanal formulation with doxicycline was so effective in eliminating $E$. faecalis from the root canal as the $2 \%$ chlorhexidine and it could be considered an alternative of intracanal dressings.

\section{CONCLUSION}

The discoveries of this study confirmed the efficacy of new formulations of intracanal medicament with $3 \%$ doxycycline or $2 \%$ chlorhexidine in eliminating E. faecalis from root canals system, and suggest their use as possible intracanal dressings.

\section{REFERENCES}

1. Sundqvist G, Figdor D, Persson S, Sjogren U. Microbiologic analysis of teeth with failed endodontic treatment and the outcome of conservative re-treatment. Oral Surg Oral Med Oral pathol Oral Radiol, Endod 1998;85(1):86-93.

2. Chivatxaranukul P, Dashper SG, Messer HH. Dentinal tubule invasion and adherence by Enterococcus faecalis. International Endodontic Journal 2008;41(10):873-882.

3. Siqueira JF Jr, Rocas IN. Clinical implications and microbiology of bacterial persistence after treatment procedures. J Endod 2008;34(11):1291-1301, e1293.

4. Greenstein G, Berman C, Jaffin R. Chlorhexidine. An adjunct to periodontal therapy. J Periodontol 1986;57(6):370-377.

5. Ferraz CC, Gomes BP, Zaia AA, Teixeira FB, Souza-Filho FJ. In vitro assessment of the antimicrobial action and the mechanical ability of chlorhexidine gel as an endodontic irrigant. J Endod 2001;27(7):452-455.

6. Ohara P, Torabinejad M, Kettering JD. Antibacterial effects of various endodontic irrigants on selected anaerobic bacteria. Endod Dent Traumatol 1993;9(3):95-100.

7. Gendron R, Grenier D, Sorsa T, Mayrand D. Inhibition of the activities of matrix metalloproteinases 2, 8 and 9 by chlorhexidine. Clini Diagn Lab Immunol 1999;6(3):437-439.

8. Khademi AA, Mohammadi Z, Havaee A. Evaluation of the antibacterial substantivity of several intracanal agents. Australian endodontic journal: the journal of the Australian Society of Endodontology Inc 2006;32(3):112-115.

9. Mohammadi Z, Abbott PV. The properties and applications of chlorhexidine in endodontics. International Endodontic Journal 2009;42(4):288-302.

10. Dametto FR, Ferraz CC, Gomes BP, Zaia AA, Teixeira FB, de Souza-Filho FJ. In vitro assessment of the immediate and prolonged antimicrobial action of chlorhexidine gel as an endodontic irrigant against Enterococcus faecalis. Oral Surg Oral Med Oral Pathol Oral Radiol Endodont 2005;99(6): 768-772.

11. Kandaswamy D, Venkateshbabu N, Gogulnath D, Kindo AJ. Dentinal tubule disinfection with $2 \%$ chlorhexidine gel, propolis, morinda citrifolia juice, $2 \%$ povidone iodine and calcium hydroxide. Int Endod J 2010;43(5):419-423. 
12. Neelakantan P, Sanjeev K, Subbarao CV. Duration-dependent susceptibility of endodontic pathogens to calcium hydroxide and chlorhexidene gel used as intracanal medicament: an in vitro evaluation. Oral Surg Oral Med Oral Pathol Oral Radiol Endod 2007;104(4):e138-141.

13. Torabinejad M, Khademi AA, Babagoli J, Cho Y, Johnson WB, Bozhilov K, Kim J, Shabahang S. A new solution for the removal of the smear layer. J Endod 2003;29(3):170-175.

14. Sapadin AN, Fleischmajer R. Tetracyclines: nonantibiotic properties and their clinical implications. Journal of the American Academy of Dermatology 2006;54(2):258-265.

15. Molander A, Dahlen G. Evaluation of the antibacterial potential of tetracycline or erythromycin mixed with calcium hydroxide as intracanal dressing against enterococcus faecalis in vivo. Oral Surg Oral Med Oral Pathol Oral Radiol Endodont 2003; 96(6):744-750.

16. Torabinejad M, Johnson WB. Irrigation solution and methods for use. US Patent 20030235804. United States: Dentsply International, York, PA 2003.

17. Kamberi B, Bajrami D, Stavileci M, Omeragiq S, Dragidella F, Kocani F. The antibacterial efficacy of biopure MTAD in root canal contaminated with Enterococcus faecalis. ISRN Dentistry 2012;2012:390526.

18. Shabahang S, Torabinejad M. Effect of MTAD on Enterococcus faecalis-contaminated root canals of extracted human teeth. Journal of Endodontics 2003;29(9):576-579.

19. Tay FR, Pashley DH, Loushine RJ, Doyle MD, Gillespie WT, Weller RN, King NM. Ultrastructure of smear layer-covered intraradicular dentin after irrigation with BioPure MTAD. Journal of Endodontics 2006;32(3):218-221.

20. Gomes BP, Souza SF, Ferraz CC, Teixeira FB, Zaia AA, Valdrighi L, Souza-Filho FJ. Effectiveness of $2 \%$ chlorhexidine gel and calcium hydroxide against Enterococcus faecalis in bovine root dentine in vitro. Int Endod J 2003;36(4):267-275.

21. Lima RK, Guerreiro-Tanomaru JM, Faria-Junior NB, TanomaruFilho M. Effectiveness of calcium hydroxide-based intracanal medicaments against Enterococcus faecalis. Int Endod J 2012;45(4):311-316.

22. Vanni JR, Santos R, Limongi O, Guerisoli DMZ, Capelli A, Pécora JD. Influence of cervical preflaring on determination of apical file size in maxillary molars: SEM analysis. Brazilian Dent J 2005;16(3):181-186.

23. Delgado RJ, Gasparoto TH, Sipert CR, Pinheiro CR, Moraes IG, Garcia RB, Bramante CM, Campanelli AP,
Bernardineli N. Antimicrobial effects of calcium hydroxide and chlorhexidine on Enterococcus faecalis. J Endod 2010;36(8): 1389-1393.

24. Portenier I, Waltimo T, Orstavik D, Haapasalo M. Killing of Enterococcus faecalis by MTAD and chlorhexidine digluconate with or without cetrimide in the presence or absence of dentine powder or BSA. J Endo 2006;32(2):138-141.

25. Mohammadi Z, Abbott PV. Antimicrobial substantivity of root canal irrigants and medicaments: a review. Australian Endodontic journal: the Journal of the Aust Soc Endod Inc 2009;35(3):131-139.

26. Greenstein G, Polson A. The role of local drug delivery in the management of periodontal diseases: a comprehensive review. J Periodontol 1998;69(5):507-520.

27. Pinheiro ET, Gomes BP, Ferraz CC, Sousa EL, Teixeira FB, Souza-Filho FJ. Microorganisms from canals of root-filled teeth with periapical lesions. Int Endod J 2003;36(1):1-11.

28. Versiani MA, Pecora JD, Sousa-Neto MD. Microcomputed tomography analysis of the root canal morphology of singlerooted mandibular canines. Int Endod J 2013.

29. Singla MG, Garg A, Gupta S. MTAD in endodontics: an update review. Oral Surg Oral Medi Oral Pathol Oral Radiol Endod 2011;112(3):e70-76.

30. Gomes BP, Ferraz CC, Vianna ME, Berber VB, Teixeira FB, Souza-Filho FJ. In vitro antimicrobial activity of several concentrations of sodium hypochlorite and chlorhexidine gluconate in the elimination of Enterococcus faecalis. Int Endod J 2001;34(6):424-428.

31. Siqueira JF Jr, Batista MM, Fraga RC, de Uzeda M. Antibacterial effects of endodontic irrigants on black-pigmented gram-negative anaerobes and facultative bacteria. J Endod 1998;24(6):414-416.

32. Zehnder M. Root canal irrigants. J Endod 2006; 32(5):389-398.

33. Vivacqua-Gomes N, Ferraz CC, Gomes BP, Zaia AA, Teixeira $\mathrm{FB}$, Souza-Filho FJ. Influence of irrigants on the coronal microleakage of laterally condensed gutta-percha root fillings. Int Endod J 2002;35(9):791-795.

34. Basrani BR, Manek S, Sodhi RNS, Fillery E, Manzur A. Interaction between sodium hypochlorite and chlorhexidine gluconate. J Endod 2007;33(8):966-969.

35. Kumar S, Patel S, Tadakamadla J, Tibdewal H, Duraiswamy P, Kulkarni S. Effectiveness of a mouthrinse containing active ingredients in addition to chlorhexidine and triclosan compared with chlorhexidine and triclosan rinses on plaque, gingivitis, supragingival calculus and extrinsic staining. Int J Dent Hyg 2013;11(1):35-40. 